\title{
The Anxiety Status of Chinese Medical Workers During the Epidemic of COVID-19: A Meta-Analysis
}

\author{
Rong Pan*, Liqing Zhang*, and Jiyang Pan ${ }^{\bowtie}$ \\ Department of Psychiatry, The First Affiliated Hospital of Jinan University, Guangzhou, China
}

Objective To analysis the anxiety status of Chinese medical workers during the epidemic of COVID-19 by meta-analysis method.

Methods CNKI, VIP, WanFang Data, SinoMed, PubMed, Cochrane, EMBASE, MEDLINE, Scopus, Google Scholar and other databases were searched to collect literature on the anxiety status of Chinese medical workers during the epidemic of COVID-19. The retrieval time is from the database construction to 11/03/2020. Meta-analysis was performed on the included articles by using Stata 16.0 software.

Results A total of 7 articles were included, with a total sample size of 7,741 people. Meta-analysis using the random effects model showed that the anxiety score of Chinese medical during the epidemic of COVID-19 was significantly higher than that of the national norm in each study, the difference was statistically significant [SMD $(95 \% \mathrm{CI})=1.145(0.705-1.584), \mathrm{p}<0.001]$.

Conclusion The anxiety level of Chinese medical workers has increased significantly during the epidemic of COVID-19.

Psychiatry Investig 2020;17(5):475-480

Key Words Medical staff, COVID-19, Anxiety, Meta-analysis, China.

\section{INTRODUCTION}

In December 2019, the 2019 Novel Coronavirus (COVID-19) broke out in Wuhan. On January 20, 2020, COVID-19 was included in category B infectious disease and managed by category A. ${ }^{1}$ With the spread of the epidemic, COVID-19 has become a public health emergency of International Concern (PHEIC). Acute respiratory infectious diseases have always been major threats to people's lives and health which every outbreak was a painful experience in human history. From SARS in 2003 to H5N1 in 2004, from Influenza A (H1N1) in 2009 to COVID-19 in 2019, it is reported that new acute respiratory infectious diseases are the ones having the highest mortality. ${ }^{2,3}$ Due to the COVID-19 is highly contagious, widespread and there is no specific drug, 4,5 medical workers are facing hitherto unknown challenges in both physical and men-

Received: April 2, 2020 Revised: April 11, 2020

Accepted: April 13, 2020

$\triangle$ Correspondence: Jiyang Pan, $\mathrm{PhD}$

Department of Psychiatry, The First Affiliated Hospital of Jinan University, Guangzhou, Guangdong 510632, China

Tel: +86 18675872910, E-mail: jiypan@163.com

*These authors contributed equally to this work.

(c) This is an Open Access article distributed under the terms of the Creative Commons Attribution Non-Commercial License (https://creativecommons.org/licenses/bync/4.0) which permits unrestricted non-commercial use, distribution, and reproduction in any medium, provided the original work is properly cited. tal health. Excessive tension and anxiety are gradually spreading among medical staff. Thus, we collect studies about the anxiety status of medical staff after the outbreak of the COVID-19 from March 11, 2020, to March 11, 2020, and then performed this meta-analysis, so that the more reliable data could be obtained to evaluate the situation objectively and accurately, and to provide feasible and effective methods of improving the mental health status of the medical workers.

\section{METHODS}

\section{Search strategy}

Chinese databases such as CNKI, VIP, Wanfang Data, SinoMed and English databases such as PubMed, Cochrane, EMBASE, MEDLINE, Scopus and Google Scholar were searched to collect literature on the anxiety status of medical staff after the outbreak of COVID-19. The search period was from database establishment to March 11, 2020. References were also searched to ensure that all relevant articles were included in the study. The following search terms were used: ("novel coronavirus" OR "novel coronavirus pneumonia" OR "new coronavirus" OR "2019-nCoV” OR "SARS-CoV-2" OR “COVID-19" OR "NCP”) AND (“mental" OR "psychology" OR "anxiety"). And The study publication time was limited to "2019-2020." The search strategy was decided after discussion by two in- 
vestigators.

\section{Inclusion and exclusion criteria}

Studies were eligible for inclusion if they met the following criteria: 1) subjects were medical staff in China; 2) study time is after the outbreak of COVID-19;3) the method was a questionnaire survey; 4 ) the scale used in the study included the Self-Rating Anxiety Scale (SAS); 5) the mean and standard deviation of anxiety scores of medical staff could be obtained in the experimental results.

Excluded studies met any of the following criteria: 1) without full text or data not available; 2) serious flaws in the study's design; 3) statistical methods are wrong; 4) overlapping or duplicate publications; 5) reviews, abstracts, letters, case reports, case series, editorials, and commentaries; 6) qualitative research.

\section{Study selection and data extraction}

All articles were screened independently by two investigators according to the inclusion and exclusion criteria. If the investigator has different opinions, discuss them together, and consult other experts when agreement cannot be reached after discussion. For each study, the following characteristics were collected: title, first author, publication year, country of the study, sample size, research method, object of study, research content, important results and conclusions. Cross-check after data extraction.

\section{Quality assessment of included studies}

The quality of included studies was assessed by two investigators independently using the Strengthening the Reporting of Observational Studies in Epidemiology (STROBE) Statement version 4 . The assessment included 22 items covering study design, setting, participants, variables, data sources/measurements, bias, study size, quantitative variables, and statistical methods. ${ }^{6}$ Each item is given a score of 1 , and the final result of the assessment was decided after discussion.

\section{Statistical analysis}

Use stata16.0 software for data statistics and analysis. The Chinese norm of SAS $(29.78 \pm 10.07)$ was used as the control group. ${ }^{7}$ The heterogeneity among studies was checked by the $\mathrm{Q}$ test and forest plots. If the $\mathrm{p}$ value for the heterogeneity test was $>0.10$, we considered that the included studies have good homogeneity and performed Mantel-Haenszel method-based fixed effects model..$^{8}$ Otherwise, the DerSimonian and Laird method-based random effects model was performed. The effect size uses standardized mean difference (SMD). Funnel chart and Egger test were done to evaluate for possible publication bias, and the test level was $\alpha=0.05$.

\section{RESULTS}

\section{Extraction process and study characteristics}

Through the retrieval of the above databases, 319 documents were finally identified according to the search strategy. Eventually, 7 studies $^{9-15}$ were included in our meta-analysis, 2 of which were in Chinese and 5 in foreign languages. Our initial search and the process of study selection are summarized in Figure 1. The main characteristics of the included studies are shown in Table 1.

\section{The anxiety status of Chinese medical workers during the epidemic of COVID-19}

Stata16.0 software was applied to test the heterogeneity of the 7 studies, $I^{2}=99.0 \%, p<0.001$, which indicated that there was significant heterogeneity among the studies. Therefore, the random effects model was performed and the effect sizes were pooled. Our results revealed that the anxiety score of Chinese medical workers during the epidemic of COVID-19 was significantly higher than that of the national norm in each study, the difference was statistically significant [SMD $(95 \%$ $\mathrm{CI})=1.145$ (0.705-1.584), $\mathrm{p}<0.001$; Table 2, Figure 2]. The results also reminded us that the anxiety status of Chinese medical staff may be related to COVID-19.

\section{Subgroup analyses}

Considering that the three included studies only investigated nurses' anxiety status, we performed a subgroup analysis that revealed a significant increase in the anxiety status among both nurses [SMD (95\% CI) $=1.296(0.269-2.324), \mathrm{p}=0.013$ ] and medical workers [SMD $(95 \% \mathrm{CI})=1.036(0.478-1.595)$,

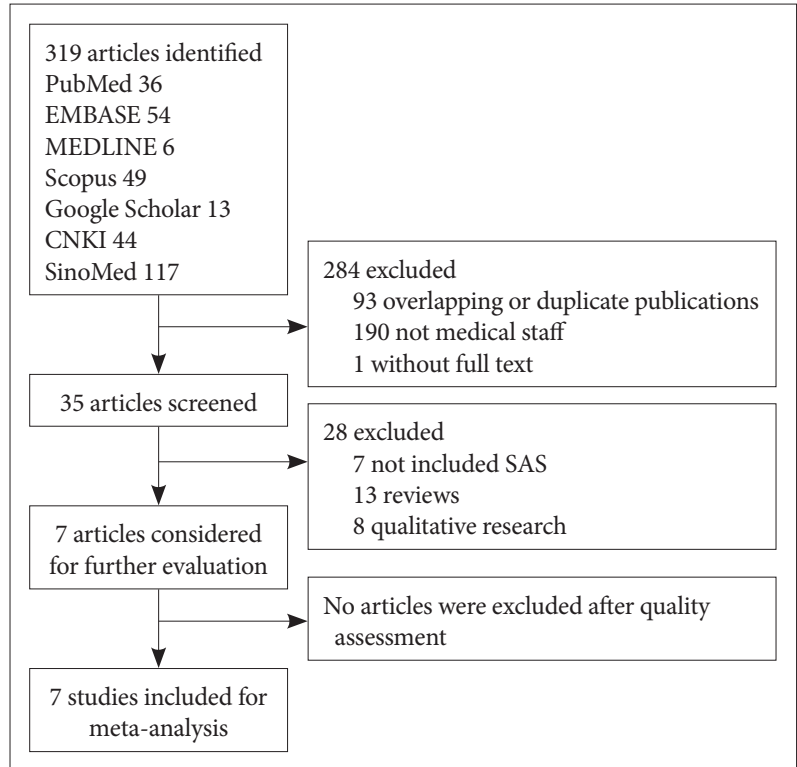

Figure 1. Flow diagram of the included studies. 
Table 1. Basic characteristics of included studies

\begin{tabular}{|c|c|c|c|c|c|}
\hline Author & Region & $\begin{array}{l}\text { Sample } \\
\text { size }\end{array}$ & Study subjects & Main results & $\begin{array}{c}\text { Quality } \\
\text { assessment }\end{array}$ \\
\hline Jizheng et al. ${ }^{9}$ & Fuyang, China & 230 & $\begin{array}{l}\text { Front-line medical staff of Fuyang city } \\
\text { second people's hospital }\end{array}$ & $\begin{array}{l}\text { SAS: } 42.91 \pm 10.89 \\
\text { PTSD-SS: } 42.92 \pm 17.88\end{array}$ & 15 \\
\hline Jia et al. ${ }^{10}$ & Mianyang, China & 867 & Nurse of Mianyang Central Hospital & $\begin{array}{l}\text { SAS: } 34.97 \pm 5.493 \\
\text { TAF: } 8.33 \pm 5.456\end{array}$ & 14 \\
\hline Junhua et al. ${ }^{11}$ & Wuhan, China & 126 & $\begin{array}{l}\text { Front-line medical staff with confirmed or } \\
\text { suspected novel coronavirus infection }\end{array}$ & $\begin{array}{l}\text { PHQ-15: }(9.72 \pm 1.604) /(3.47 \pm 1.55) \\
\text { SAS: }(45.47 \pm 1.405) /(43.47 \pm 2.779) \\
\text { SDS: }(51.25 \pm 1.611) /(35.00 \pm 3.055) \\
\text { PCL-C: }(34.81 \pm 1.36) /(30.75 \pm 1.159) \\
\text { PSQI: }(14.00 \pm 3.874) /(10.36 \pm 3.39)\end{array}$ & 18 \\
\hline Jijun et al. ${ }^{12}$ & Sichuan, China & 106 & Front-line nurses & $\begin{array}{l}\text { PSQI: } 7.96 \pm 2.12 \\
\text { SAS: } 56.39 \pm 6.99\end{array}$ & 13 \\
\hline Wenhui et al. ${ }^{13}$ & Hangzhou, China & 207 & $\begin{array}{l}\text { Front-line nurse of Xixi Hospital of } \\
\text { Hangzhou }\end{array}$ & SAS: $35.43 \pm 6.66$ & 14 \\
\hline Siyu et al. ${ }^{14}$ & China & 5,393 & $\begin{array}{l}\text { Physicians, Nurses, Clinical Assistants and } \\
\text { medical students }\end{array}$ & $\begin{array}{l}\text { SAS: } 32.80 \pm 8.60 \\
\text { ISI: } 6.10 \pm 5.00\end{array}$ & 18 \\
\hline Liu et al. ${ }^{15}$ & China & 512 & Front-line medical staff & SAS: $39.56 \pm 8.91$ & 19 \\
\hline
\end{tabular}

SAS: Self-rating Anxiety Scale, PTSD-SS: Post-Traumatic Stress Disorder Self-rating Scale, TAF: The Triage Assessment Form, PHQ-15: Patient Health Questionnaire, SDS: Self-rating Depression Scale, PCL-C: Post-Traumatic Stress Disorder self-assessment scale (PTSD ChecklistCivilian Version), PSQI: Pittsburgh Sleep Quality Index, ISI: Insomnia Severity Index

Table 2. Meta-analysis of medical staff's anxiety status during the epidemic of COVID-19

\begin{tabular}{lccc}
\hline \multirow{1}{*}{ Studies } & \multicolumn{3}{c}{ Comparison with Chinese anxiety norm } \\
\cline { 2 - 4 } & SMD & 95\% CI & Weight $\%$ \\
\hline Jizheng et al. $^{9}$ & 1.286 & $1.137-1.435$ & 14.29 \\
Jia et al. $^{10}$ & 0.616 & $0.526-0.706$ & 14.44 \\
Junhua et al. $^{11}$ & 1.531 & $1.338-1.724$ & 14.13 \\
Jijun et al. $^{12}$ & 2.701 & $2.476-2.926$ & 13.99 \\
Wenhui et al. $^{13}$ & 0.587 & $0.437-0.736$ & 14.28 \\
Siyu et al. ${ }^{14}$ & 1.005 & $0.896-1.115$ & 14.39 \\
Liu et al. $^{15}$ & 0.340 & $0.276-0.404$ & 14.48 \\
Overall & 1.145 & $0.705-1.584$ & 100.00 \\
Heterogeneity test: $\chi^{2}=591.07$ & $\mathrm{df}=6(\mathrm{p}<0.001)$ & $\mathrm{I}^{2}=99.0 \%$ \\
Test of SMD: $\mathrm{z}=5.10(\mathrm{p}<0.001)$ & & \\
\hline
\end{tabular}

SMD: standardized mean difference

\begin{tabular}{|c|c|c|c|}
\hline \multicolumn{2}{|l|}{ Study } & & $\%$ \\
\hline \multicolumn{2}{|l|}{ ID } & $\operatorname{SMD}(95 \% \mathrm{CI})$ & Weight \\
\hline Jizheng et al. ${ }^{9}$ & & $1.29(1.14,1.44)$ & 14.28 \\
\hline Jia et al. ${ }^{10}$ & + & $0.62(0.53,0.71)$ & 14.44 \\
\hline Junhua et al. ${ }^{11}$ & $\leftarrow$ & $1.53(1.34,1.72)$ & 14.13 \\
\hline Jijun et al. ${ }^{12}$ & & $\leftarrow 2.70(2.48,2.93)$ & 13.99 \\
\hline Wenhui et al. ${ }^{13}$ & + & $0.59(0.44,0.74)$ & 14.28 \\
\hline Liu et al. ${ }^{15}$ & t & $1.01(0.90,1.11)$ & 14.39 \\
\hline Siyu et al. ${ }^{14}$ & - & $0.34(0.28,0.40)$ & 14.48 \\
\hline Overall (I-squared= & & $1.14(0.71,1.58)$ & 100.00 \\
\hline \multicolumn{4}{|c|}{ Note: weights are from random effects'analysis } \\
\hline-2.93 & & 2.93 & \\
\hline
\end{tabular}

Figure 2. Forest plots of medical staff's anxiety status during the epidemic of COVID-19. $\mathrm{p}<0.001]$ during the epidemic of COVID-19 (Figure 3A). Because each study had a different survey time period, we divided the included studies into two subgroups according to whether the survey time period was in January or February. The analysis showed that anxiety scores decreased over time, but the scores of medical workers were higher than the national norm in the studies of January [SMD $(95 \% \mathrm{CI})=1.604$ $(0.417-2.791), \mathrm{p}=0.008]$ and February $[\mathrm{SMD}(95 \% \mathrm{CI})=0.808$ $(0.419-1.197), \mathrm{p}<0.001]$, and the difference was statistically significant (Figure 3B). Besides, subgroup analysis showed that the larger sample size of the study may have the lower the anxiety score. However, the anxiety scores of medical workers with the sample size $<500[\mathrm{SMD}(95 \% \mathrm{CI})=1.523(0.739-2.307)$, $\mathrm{p}<0.001]$ and $>500[\mathrm{SMD}(95 \% \mathrm{CI})=0.652(0.283-1.020)$, $\mathrm{p}=$ 0.001 ] were both higher than the national norm. Wuhan is the city with the earliest and most serious outbreak of COVID-19 in China. To examine whether the severity of the pandemic would exert an influence on our results, the study by Mei Junhua was excluded to perform a meta-analysis. The results still showed a statistical difference, and the anxiety scores of Chinese medical staff in 6 studies was significantly higher than the national norm [SMD (95\% CI) $=1.081(0.618-1.543)$, $\mathrm{p}<0.001]$. Unfortunately, all the subgroup analyses above failed to reduce the heterogeneity, indicating that study subject (only nurses or doctors included), survey time period, sample size, and severity of the pandemic may not be the sources of heterogeneity. 


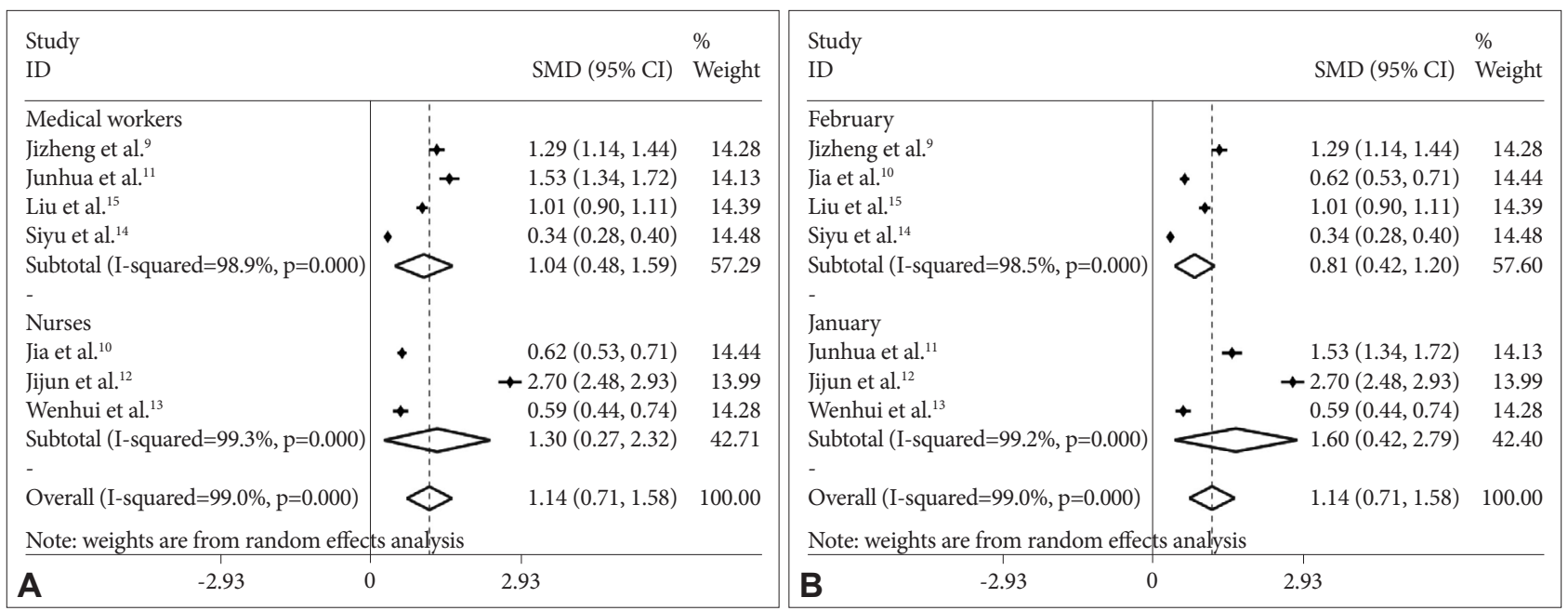

Figure 3. Forest maps of subgroup analysis. A: Subgroup analysis by study subject. B: Subgroup analysis by survey time period.

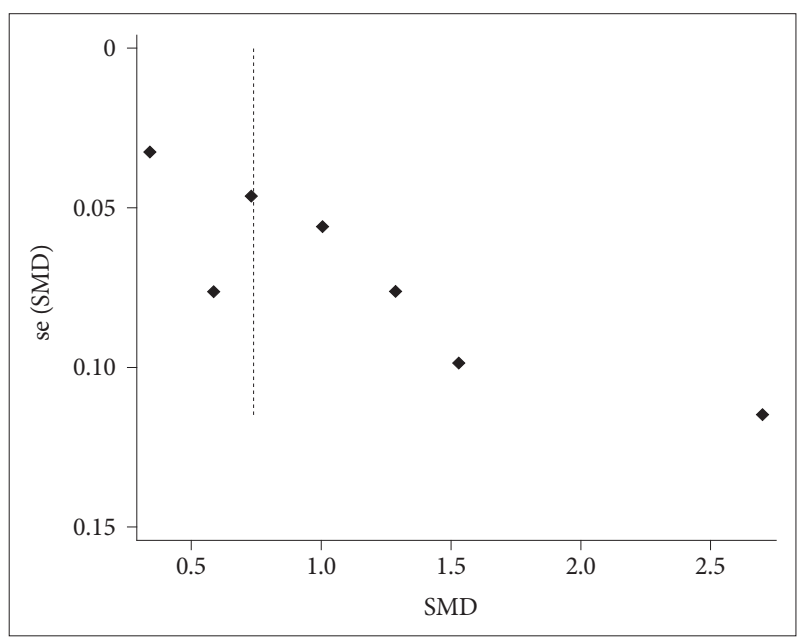

Figure 4. Funnel plot of potential publication bias for included studies. SMD: standardized mean difference.

\section{Sensitivity analyses}

Sensitivity analyses were performed to assess the influence of each individual study on the pooled SMD. As the homogeneity of the included studies in this study is not good, a single study involved in the pooled meta-analysis was excluded in each round of analysis. Nevertheless, the directions of the forest plots were almost the same, and the corresponding SMD were not changed considerably, suggesting that the results of this meta-analysis are credible (data also not shown). ${ }^{16}$

\section{Publication bias}

The funnel plot was drawn to assess the publication bias of the included studies (Figure 4), and its shape revealed some evidence of asymmetry, suggesting the possibility of publication bias. Further quantitative Egger test was conducted, and the $\mathrm{p}$ value for Egger test was 0.007 . Thus, publication bias existed in this meta-analysis. The reasons may be the insufficient sample sizes of some included studies and the significant clinical heterogeneity among the studies. ${ }^{17}$

\section{DISCUSSION}

Anxiety is a common emotional disturbance that may occur in medical workers, especially when a public health emergency happened. Understanding the mental health response after a public health emergency might help medical workers prepare for a disaster. ${ }^{18}$ From the SARS epidemic, we learned that when confronted with an unknown infectious disease, the inability of health officials to deal effectively with the crisis led to nursing staff losing their emotional control and become anxious. ${ }^{19}$ Besides, research by Sang Min Lee in 2015 found that during the acute infection stage, performing MERS-related tasks could have resulted in serious psychological distress. ${ }^{20}$ Although flu happened almost every year, medical staff might still feel stressed and kind of anxious when it breaks out. ${ }^{21,22}$

The study aimed at knowing more comprehensively about the anxiety status of Chinese medical workers during the epidemic of COVID-19, including 7 studies with 7,441 people. According to the results, we found that they have higher scores of anxiety although with heterogeneity, which was consistent with the results of previous studies on the anxiety level of medical staff during emergent events of public health outbreaks. ${ }^{23,24}$

The main reasons for this result are as follows: 1) The occurrence of COVID-19 is unexpected and the virus is highly contagious in the populations. The confirmed cases are rising rapidly within a short time and many front-line medical staff have also been infected. Some medical staff may not immediately adapt to the sudden increase in clinical work stress and psychological stress. 2) Most hospitals lack experience in dealing with emergent events of public health and do not conduct 
timely psychological interventions for medical staff. Most medical staff have not systematically learned about emergency response plans and have not participated in training courses about emergent events of public health so they are inexperienced. ${ }^{12}$ Some studies have found that timely psychological intervention measures and emergency plans are effective methods to reduce the anxiety of medical staff in the face of public health emergency. ${ }^{25} 3$ ) Extremely high work intensity and strong psychological pressure. Several facts account for the phenomenon: a huge number of people were infected with COVID-19, work every day without rotation, no specific drugs have been developed and the relationship between doctors and patients was still intense and so on. Yuan et al. ${ }^{26}$ showed that the anxiety status of medical staff was positively associated with work intensity. 4) There may be a concern that the payoff is not equal to the giving. Some studies revealed that, for medical workers, the smaller payoff and the greater giving may cause the heavier anxiety symptoms. ${ }^{27,28}$ During the epidemic of COVID-19, medical workers were on the front line of fighting against the virus, and at a high risk of infection at any time. Therefore, if welfare treatment is not improved to some extent, it may tend to induce anxiety.

Psychological factors have a certain impact on the fight against 2019-nCoV, for example, anxiety may not only affect the medical workers' attention, understanding, and decision making ability, ${ }^{29-31}$ but also result in decreased resistance, insomnia and other adverse physical and mental reactions. ${ }^{32,33}$ The coping mechanisms, developed by Aguilera ${ }^{34}$ based 1994 on Caplan's theory, refer to the usual patterns of reaction when a subject faces a problem. Medical workers are expected to believe that they can effectively manage current situations, and the perceived control of certain circumstances will affect their choice and insistence on coping strategies. ${ }^{25}$ Some coping strategies like objectively analyzing current situations, praising yourself for some good performance, making a phone call with family, or exchanging ideas with colleagues will help decrease the anxiety status of medical workers. Besides, on Jan 27, 2020, the National Health Commission of China published a national guideline of psychological crisis intervention for $2019-\mathrm{nCoV}^{35}$ Wuhan government implemented some policies to solve the mental health problems of the medical staff in Wuhan. Four psychological intervention teams were set up, including the psychosocial response team, the psychological intervention technical support team, the psychological intervention medical team and the psychological assistance hotline teams, which are effective methods of improving the mental health status of the medical workers.

There are still some limitations in this study. Firstly, the quantity of included studies is small. Secondly, only studies containing the Self-Rating Anxiety Scale were analyzed, and other scales in the studies were not analyzed. Thirdly, there was a large heterogeneity among the included studies, for which we will discuss and analyze later.

According to the Cochrane Handbook for Systematic Reviews of Interventions, heterogeneity in meta-analysis can be divided into three categories: clinical heterogeneity, methodological heterogeneity, and statistical heterogeneity. ${ }^{36}$ The study methods of 7 studies included in our meta-analysis were to use SAS to assess the anxiety status of medical staff. The overall mean and standard deviation were calculated by Statistical Product and Service Solutions (SPSS) in all 7 studies. Therefore, there was no significant heterogeneity in the methodology and statistics.

The problem we face is that the clinical heterogeneity is large, for example, the anxiety score is significantly lower in the study of $\mathrm{Pu}$ Jia. After analysis, the authors found that the investigated area, Sichuan, is an area with a low infection rate of COVID-19, and the severity of the epidemic was mild. In addition, the hospital established a working group in time to provide training and psychological intervention for medical staff, so the psychological pressure faced by medical staff is smaller and less anxious than in other areas with severe epidemic situations. ${ }^{10}$ But after the subgroup analyses, the heterogeneity was not reduced successfully. Therefore, we speculate that the main source of the heterogeneity may be the insufficient quantity of our included studies, causing limited data for analysis. However, after changing the model and sensitivity analyses, it was found that the results of Meta-analysis were not reversed, and the analysis results were statistically significant, so the conclusions of this study were still reliable. ${ }^{16}$

In summary, the COVID-19 has brought great challenges to clinical medical staff, and the anxiety level of Chinese medical workers has increased significantly during the epidemic of COVID-19. Thus, we call on the departments concerned and medical institutions to pay more attention to the physical and mental health of front-line medical staff and to provide timely psychological intervention measures and social support for them, ${ }^{37,38}$ ensuring that medical staff may confront COVID-19 with the best physical and mental status. ${ }^{31,39}$

\section{Acknowledgments}

The author(s) gratefully acknowledge the following financial support for the research, authorship, and/or publication of this article: the National Natural Science Foundation of China (81871036). Useful suggestions given by Zhijin Hong and Chaonan Liu are also acknowledged.

\section{Conflicts of Interest}

The authors have no potential conflicts of interest to disclose.

\section{Author Contributions}

Conceptualization: Rong Pan, Liqing Zhang. Data curation: Rong Pan, Liqing Zhang. Formal analysis: Rong Pan, Liqing Zhang. Funding acquisition: Jiyang Pan. Investigation: Rong Pan, Liqing Zhang. Methodology: 
Rong Pan, Liqing Zhang. Project administration: Rong Pan, Liqing Zhang. Resources: Rong Pan, Liqing Zhang. Software: Rong Pan, Liqing Zhang. Supervision: Jiyang Pan. Validation: Rong Pan, Liqing Zhang. Visualization: Rong Pan, Liqing Zhang. Writing_-original draft: Rong Pan, Liqing Zhang. Writing_review \& editing: Rong Pan, Liqing Zhang, Jiyang Pan.

\section{ORCID iDs}

$\begin{array}{ll}\text { Rong Pan } & \text { https://orcid.org/0000-0003-4523-8576 } \\ \text { Liqing Zhang } & \text { https://orcid.org/0000-0002-1611-6812 } \\ \text { Jiyang Pan } & \text { https://orcid.org/0000-0003-2802-0137 }\end{array}$

\section{REFERENCES}

1. National Health Commission of the People's Republic of China. Available at: http://www.gov.cn/zhengce/zhengceku/2020-01/21/content_5471164.htm. Accessed March 12, 2020.

2. Yang L, Yanrui J, Fengli G. A study review of psychological status of health care professionals engaged in emerging acute respiratory infectious diseases. Chin Nurs Manag 2019;19:83-86.

3. World Health Organization. Available at: http://www.euro.who.int.influenza. Accessed March 12, 2020.

4. Cheng VCC, Wong SC, To KKW, Ho PL, Yuen KY. Preparedness and proactive infection control measures against the emerging novel coronavirus in China. J Hospital Infect 2020;104:254-255.

5. Cheng ZJ, Shan J. 2019 Novel Coronavirus: Where We Are and What We Know. Munich: Infection; 2020.

6. Elm EV, Altman DG, Egger M, Pocock SJ, Gotzsche PC, Vandenbroucke JP. Strengthening the reporting of observational studies in epidemiology (STROBE) statement: guidelines for reporting observational studies. BMJ 2007;335:806-808.

7. Yuanming Z, Yanlin H. Manual of Psychiatric Rating Scale. Changsha: Hunan Science \& Technology Press; 2015.

8. Mantel N, Haenszel W. Statistical aspects of the analysis of data from retrospective studies of disease. J Natl Cancer Inst 1959;22:719-748.

9. Jizheng H, Mingfeng H, Tengda L, Ake R, Xiaoping Z. Mental health survey of 230 medical staff in a tertiary infectious disease hospital for COVID-19 [J/OL]. Chin J Indust Hygiene Occup Diseases 2020;38:E001.

10. Jia P, Guirong L, Lulu C, Yuanchen W, Linglin X. Investigation and analysis of the psychological status of the clinical nurses in a class A hospital facing the novel coronavirus pneumonia. Chongqing Med 2020;49:1-6.

11. Junhua M, Qi Z, Xue G, Lijuan L, Zhongwen Z, Jing W, et al. Analysis of psychological and sleep state of medical stuff with novel coronavirus pneumonia. Herald Med 2020;39:345-349.

12. Jijun W, Xian S, Fei C, Yuanjie D, Dechun C, Xingcao J, et al. Investigation on sleep quality of first line nurses in fighting against novel coronavirus pneumonia and its influencing factors. Nurs Res China 2020; 34:558-562.

13. Wenhui Z, Er L, Yi Z. Investigation and countermeasures of anxiety of nurses in a designated hospital of novel coronavirus pneumonia in Hangzhou. Health Res 2020;40:130-133.

14. Siyu C, Xia M, Wen W, Cui L, Yang W, Liu S, et al. Mental health status and coping strategy of medical workers in China during The COVID-19 outbreak. medRxiv 2020 [Epub ahead of print].

15. Liu CY, Yang YZ, Zhang XM, Xu X, Dou QL, Zhang WW. The prevalence and influencing factors for anxiety in medical workers fighting COVID-19 in China: a cross-sectional survey. Available at: https://www. researchgate.net/publication/339785132 .Accessed March 12, 2020.

16. Chen G, Zhu L, Yang Y, Long Y, Li X, Wang Y. Prognostic role of neutrophil to lymphocyte ratio in ovarian cancer: a meta-analysis. Technol Cancer Res Treat 2018;17:1533033818791500.

17. Lin L, Chu H, Murad MH, Hong C, Qu Z, Cole SR, et al. Empirical comparison of publication bias tests in meta-analysis. J Gen Intern Med 2018;33:1260-1267.

18. von Keudell A, Koh KA, Shah SB, Harris MB, Smith M, Rodriguez EK, et al. Mental health after the Boston marathon bombing. Lancet Psy- chiatry 2016;3:802-804.

19. Chen R, Chou KR, Huang YJ, Wang TS, Liu SY, Ho LY. Effects of a SARS prevention programme in Taiwan on nursing staff's anxiety, depression and sleep quality: a longitudinal survey. Int J Nurs Stud 2006; 43:215-225.

20. Lee SM, Kang WS, Cho AR, Kim T, Park JK. Psychological impact of the 2015 MERS outbreak on hospital workers and quarantined hemodialysis patients. Compr Psychiatry 2018;87:123-127.

21. Jones JH, Salathé M. Early assessment of anxiety and behavioral response to novel swine-origin influenza A(H1N1). PLoS One 2009;4:e8032.

22. Mishra P, Bhadauria US, Dasar PL, Sandes N, Kumar S, Lalani A, et al. Knowledge, attitude and anxiety towards pandemic flu a potential bio weapon among health professionals in Indore City. Przegl Epidemiol 2016;70:41-45, 125-127.

23. Chen CS, Wu HY, Yang P, Yen CF. Psychological distress of nurses in Taiwan who worked during the outbreak of SARS. Psychiatr Serv 2005; 56:76-79.

24. Hui DS, Ko FW, Chan DP, Fok JP, Chan MC, To KW, et al. The longterm impact of severe acute respiratory syndrome (sars) on pulmonary function, exercise capacity, and quality of life in a cohort of survivors. Chest 2005;60:401-409.

25. Chen R, Chou KR, Huang YJ, Wang TS, Liu SY, Ho LY. Effects of a SARS prevention programme in Taiwan on nursing staff's anxiety, depression and sleep quality: a longitudinal survey. Int J Nurs Stud 2006;43:215-225.

26. Yuan $\mathrm{Y}$, Ying $\mathrm{C}$, Haihong $\mathrm{H}$. The status of anxiety and depression and their correlation with work intensity in medical staffs. China J Health Psychol 2019;7:25.

27. Saquib N, Zaghloul MS, Saquib J, Alhomaidan HT, Al-Mohaimeed A, Al-Mazrou A. Association of cumulative job dissatisfaction with depression, anxiety and stress among expatriate nurses in Saudi Arabia. J Nurs Manag 2019;27:740-748.

28. Davey A, Sharma P, Davey S, Shukla A. Is work-associated stress converted into psychological distress among the staff nurses: a hospitalbased study. J Family Med Prim Care 2019;8:511-516.

29. Raghunathan R, Pham MT. All negative moods are not equal: motivational influences of anxiety and sadness on decision making. Organ Behav Hum Decis Process 1999;79:56-77.

30. Maner JK, Richey JA, Cromer K, Mallott M, Lejuez CW, Joiner TE, et al. Dispositional anxiety and risk-avoidant decision-making. Pers Individ Diff 2007;42:665-675.

31. Kang L, Li Y, Hu S, Chen M, Yang C, Yang BX, et al. The mental health of medical workers in Wuhan, China dealing with the 2019 novel coronavirus. Lancet Psychiatry 2020;7:e14.

32. Enns MW, Bernstein CN, Kroeker K, Graff L, Walker JR, Lix LM, et al. The association of fatigue, pain, depression and anxiety with work and activity impairment in immune mediated inflammatory diseases. PLoS one 2018;13:e0198975.

33. Cox RC, Olatunji BO. Sleep in the anxiety-related disorders: a meta-analysis of subjective and objective research. Sleep Med Rev 2020;51: 101282.

34. Aguilera DC. Crisis Intervention: Theory and Methodology. St.Louis, MO : Mosby; 1994.

35. National Health Commission of the People's Republic of China. Available at: http://www.gov.cn/zhengce/zhengceku/2020-01/21/content_5471164.htm. Accessed April 11, 2020.

36. Shuster JJ. Cochrane Handbook for Systematic Reviews for Interventions, Version 5.1. 0. In: Julian PT Higgins, Sally Green, Editors. Chichester: Research Synthesis Methods, 2011, p.126-130.

37. Mak WW, Law RW, Woo J, Cheung FM, Lee D. Social support and psychological adjustment to SARS: the mediating role of self-care selfefficacy. Psychol Health 2009;24:161-174.

38. Xiang YT, Yang Y, Li W, Zhang L, Zhang Q, Cheung T, et al. Timely mental health care for the 2019 novel coronavirus outbreak is urgently needed. Lancet Psychiatry 2020;7:228-229.

39. Chen Q, Liang M, Li Y, Guo J, Fei D, Wang L, et al. Mental health care for medical staff in China during the COVID-19 outbreak. Lancet Psychiatry 2020;7:e15-e16. 